\title{
LA COMPOSICIÓ DE LA VERSIÓ CATALANA MEDIEVAL DEL TRESOR DE POBRES DEL MS. 864 DE LA BIBLIOTECA DE CATALUNYA. ANÀLISI DEL CONTINGUT I EDICIÓ DE LES RECEPTES DE CONFITS*
}

\author{
THE COMPOSITION OF THE CATALAN MEDIEVAL VERSION \\ OF THE THESAURUS PAUPERUM FROM THE MS. 864 \\ IN THE LIBRARY OF CATALONIA. CONTENT ANALYSIS \\ AND EDITION OF THE CANDIED FRUIT RECIPES
}

\author{
JOAN SANTANACH I SUÑOL \\ Universitat de Barcelona \\ http://orcid.org/0000-0002-7872-280X
}

\begin{abstract}
Resum: El Thesaurus pauperum de Pere Hispà és un recull de receptes mèdiques que va gaudir d'una àmplia circulació fins al segle XVIII. El caràcter pràctic del text va afavorir que els usuaris hi afegissin nombroses receptes apòcrifes, tant dins de la tradició llatina com, una vegada traduïda l'obra, dins de la catalana. L'anàlisi del contingut de la versió que se'n conserva al ms. 864 de la Biblioteca de Catalunya permet reconstruir diverses etapes de la seva composició. Entre els afegits de l'obra, hi ha cinc receptes de confits redactades en català, fins ara inèdites.
\end{abstract}

Paraules clau: Tresor de pobres; Pere Hispà; receptaris; traducció catalana; afegits apòcrifs; cuina medieval; receptes de confits.

\begin{abstract}
The Thesaurus pauperum by Petrus Hispanus is a collection of medical recipes that enjoyed huge popularity until the eighteenth century. The practical nature of the work encouraged users to add many apocryphal recipes, both within the Latin tradition and, once translated, within the Catalan tradition. The content analysis of the version conserved in MS. 864 in the Library of Catalonia makes it possible to reconstruct different stages of its composition. Among the additions to the work, there are five recipes for candied fruit written in Catalan, hitherto unpublished.
\end{abstract}

Keywords: Thesaurus pauperum; Petrus Hispanus; recipe books; Catalan translation; apocryphal additions; medieval cookery; candied fruit recipes.

\footnotetext{
* Aquest treball forma part del projecte de recerca coordinat FFI2014-53050-C5-1-P, finançat pel Ministeri d'Economia i Competitivitat espanyol, que es desenvolupa al CDRL de la Universitat de Barcelona. També s'inscriu en el marc dels treballs del Grup de Recerca Consolidat 2009 SGR 1261, Grup de Literatura i Cultura a la baixa edat mitjana, de la Generalitat de Catalunya.
} 


\section{SUMARI}

1. Els receptaris, un gènere pràctic i canviant.-2. El contingut del Tresor de pobres de la Biblioteca de Catalunya.-3. Una col·lecció unitària o composta?.-4. Divergències entre la taula de rúbriques i la col·lecció recollida al manuscrit.- 5. El conjunt de receptes no documentades a la tradició llatina.- 6. Les receptes de confits.- 7. Edició de les receptes de confits.- 8 . Conclusions.- 9. Bibliografia citada.

\section{ELS RECEPTARIS, UN GÈNERE PRÀCTIC I CANVIANT}

El Thesaurus pauperum atribuït a Pere Hispà (c. 1215-1277), que va ser papa amb el nom de Joan XXI, va gaudir d'una difusió molt important durant la baixa edat mitjana. Vinculat a l'escola de Salern, va ensenyar medicina a Siena, i més tard va exercir a Roma com a metge personal del papa Gregori X. Hauria estat durant aquest període que el llavors ja arxidiaca hauria escrit el Thesaurus pauperum, per bé que se n'hi ha discutit 1'autoria'. Sigui com sigui, l'èxit del tractat, integrat bàsicament per receptes de tipus mèdic $i$ terapèutic, es va mantenir fins ben entrat el segle XVIII. Se'n poden documentar nombroses còpies, traduccions i edicions. L'obra va circular igualment en català. L'àmplia difusió de què va ser objecte, com també el fet que es tracti d'un receptari, va afavorir que des de ben aviat fos objecte d'interpolacions, adaptacions i modificacions de tota mena ${ }^{2}$. I, això, tant dins la tradició llatina com, segons tots els indicis, dins la catalana.

Es té notícia de diversos manuscrits medievals que transmeten versions en català del Thesaurus pauperum ${ }^{3}$. S'ha discutit, sense que per ara se n'hagi tret l'entrellat, si són producte o no d'una mateixa traducció. Les divergències de contingut que hi ha entre els testimonis catalans són prou remarcables per requerir un estudi específic, del tot imprescindible abans d'emetre qualsevol afirmació sobre les relacions entre les versions de l'obra que transmeten i, no cal dir, d'emprendre'n l'edició crítica. Entre els volums en què s'han conservat versions en català del Thesaurus, cal esmentar el ms. 864 de la Biblioteca de Catalunya, objecte de l'estudi present, com també els testimonis de l'obra copiats als manuscrits 191 de la Biblioteca Episcopal de Vic, de vers

\footnotetext{
${ }^{1}$ Per al text llatí del Thesaurus, vegeu Pereira 1973. Per a un estat de la qüestió sobre el personatge i l'autoria de l'obra, vegeu Meirinhos 1996, 2005, 2013, com també la pàgina Petrus Hispanus, URL: http://ifilosofia.up.pt/meirinhos/petrushispanus/ph.

${ }^{2}$ Pereira 1973, analitza diversos d'aquests fenòmens.

${ }^{3}$ Per al context en què va sorgir, es va difondre i es va traduir al català el Thesaurus, vegeu Cifuentes 2010,pp. 42-49.
} 
la segona meitat del XIV ${ }^{4}$, i 216 de la Biblioteca Històrica de la Universitat de València, de la primera meitat del $X^{5}$. Se n'han conservat altres versions en què el grau de reelaboració sembla encara superior. Fóra el cas, potser, del Receptari de misser Joan, datat el 1466, que en seria una antologia ${ }^{6}$.

La còpia del Tresor de pobres conservada al ms. 864 de la Biblioteca de Catalunya conté un nombre important de receptes, que supera àmpliament les dues-centes. A més de les agrupacions temàtiques originals, se n'hi poden individualitzar d'altres que ens parlen del procés de composició de la col·lecció, producte d'addicions successives. Entre aquestes incorporacions hi ha receptes que no ens consta que s'hagin conservat en testimonis llatins del Thesarus i que, com veurem, és probable que hi haguessin estat afegides una vegada l'obra ja havia estat traduïda al català. És versemblant, en consequiència, que haguessin estat escrites directament en la llengua romànica. Cinc d'aquestes receptes estan dedicades a preparacions de fruita confitada.

La mateixa estructura dels receptaris, constituïts per breus unitats textuals fàcilment eliminables, substituïbles i incorporables a nous reculls, propiciava la manca d'estabilitat que s'observa en algunes colleccions pel que fa a les receptes que les conformen. El Thesaurus pauperum no n'és una excepció. Cal sumar-hi, a més, la seva condició d'obres eminentment pràctiques, sovint anònimes, a les pàgines de les quals els usuaris consignaven els seus propis coneixements, fruit de l'experiència directa. No es limitaven, doncs, a donar-los un ús passiu, sinó que hi intervenien, modificant les indicacions sobre l'elaboració de les preparacions segons els propis hàbits i formació, i fent-hi les aportacions que consideraven pertinents o útils per a un ús futur de la colllecció. Ho feien en forma d'anotacions marginals o d'addicions en folis i espais deixats en blanc, les quals eren incorporades amb

\footnotetext{
${ }^{4}$ Del text de Vic, se'n va fer una edició parcial i incompleta, publicada l'any 1892 sense nom del curador, potser atribuïble a Josep Balari i Jovany, com a complement dels núms. VII-X de la Revista Catalana; vegeu Tresor 1892.

${ }^{5}$ Vegeu Beaujouan 1972,p. 195; Cifuentes 2006, pp. 116-117, 285, BITECA, manid 1583, 1582 i 1177. Per al còdex barceloní, vegeu també la crònica d'adquisicions de la Biblioteca de Catalunya, en Biblioteca de Catalunya 1923-1927, p. 348; Escudero 1993, pp. 325, 373-374; Mateo 1959, p. 88, MCEM 135. Per al de València, Massó 1906-1912, pp. 247-257, Santanach 2015. D'aquesta darrera versió, R. Miquel i Planas en preparava, o tenia intenció de prepararne, una edició que havia de formar part d'un volum imprès en lletra gòtica, per bé que només se n'ha conservat la portadella; sí que es van publicar, en canvi, els fascicles d'aquest volum corresponents a la Tròtula de mestre Joan, l'Speculum al foder i el Flors del Tresor de beutat; vegeu Alberni 2006.

${ }^{6}$ Per al Receptari de misser Joan, datat el 1466, vegeu Escudero, Urbano, Martín 1992. El manuscrit únic de l'obra, que l'any 1914 era en mans d'Ernest Moliné i Brasés, estudiós que el va donar a conèixer i editar, Moliné 1914, actualment forma part de la Louise M. Darling Biomedical Library de la Universitat de California (UCLA), on va ingressar amb el llegat de John A. Benjamin (n'és el ms. Benj. 1.4); vegeu Cifuentes 2013. Cifuentes 2010, p. 249, n. 6, esmenta altres manuscrits potser relacionables amb la tradició catalana del Thesaurus pauperum.
} 
tota naturalitat en còpies posteriors sense cap distinció que assenyalés el seu caràcter recent. Quedaven, així, integrades a l'obra com si sempre n'haguessin format part.

La possibilitat de fer-ne un ús estrictament pràctic i d'intervenir-hi segons el propi criteri no impedia que aquests mateixos receptaris fossin alhora percebuts com a textos unitaris i no com a simples agrupacions accidentals de receptes. L'existència de taules de rúbriques que en detallen el contingut, normalment situades a l'inici de les obres, o fins i tot de pròlegs, contribuïa a potenciar la percepció entre els usuaris que les receptes, malgrat la seva volatilitat, constituïen parts d'un mateix conjunt. Els elements que els conferien cohesió - pròleg, rúbriques, remissions internes, fins i tot numeració de capítols- responien a un objectiu bàsicament funcional: presentar i facilitar la localització dels apartats que conformaven els llibres. Contribuïen igualment, al mateix temps, a dotar els receptaris d'entitat librària, i a encobrir, encara que no ho fessin de forma deliberada, la diversitat d'orígens dels elements que els formaven.

La taula de rúbriques atorgava unitat a les receptes i evidenciava la seva pertinença a la col·lecció. Ara bé, còpies successives d'aquesta col·lecció incorporaven noves divergències, que les allunyaven de l'antecedent per al qual s'havia elaborat la taula, alhora, però, que es tendia a reproduir aquesta mateixa taula sense reflectir-hi els canvis incorporats al cos del text. D'aquesta manera l'índex, preparat per a un estadi concret del receptari-que podia ser el moment de la compilació, de la traducció o bé, simplement, en enllestir-ne una còpia nova-, veia minvada la seva capacitat de reflectir el contingut efectiu del receptari. També se'n ressentia, per tant, la seva utilitat.

N'és un exemple ben conegut el del Llibre de Sent Soví, compost per a una col·lecció de receptes de transmissió remarcablement complexa. De l'obra, se'n conserven tres testimonis de significació diversa, en part perquè dos d'aquests són receptaris més extensos que han incorporat receptes de tradició sentsovinenca al seu si. Doncs bé, a l'únic testimoni que, pròpiament, forma part de la tradició directa del text, el ms. 216 de la Biblioteca Històrica de la Universitat de València, hi ha una taula de rúbriques que conté gairebé un centenar de receptes, de les quals, però, només aproximadament la meitat formen part efectivament del receptari copiat a continuació; a la col·lecció n'hi ha una vintena, en canvi, que no es van arribar a consignar a la taula, sens dubte perquè van ser incorporades al recull posteriorment a l'elaboració de l'índex ${ }^{7}$. Aquest fenomen, és a dir, l'existència de divergències remarcables

\footnotetext{
${ }^{7}$ Santanach 2006, pp. 20-22; 2010, pp. 358-366. Per a la producció i la transmissió de llibres de cuina en el context català, vegeu Santanach 2015.
} 
entre un text i la taula de rúbriques que el precedeix, s'observa també en el Tresor de pobres del ms. 864, com veurem més avall.

\section{El CONTINGUT DEL TRESOR DE POBRES DE LA BiblioteCA DE CATALUNYA}

El nucli originari del ms. 864 va ser copiat l'any 1392 per Galceran Marquet, de Barcelona. Així s'indica al colofó que hi ha al f. 96va del còdex. Hi llegim:

Ego Galserandus Marqueti, de loco Barchinone, scripsi totum istud volumen ${ }^{8}$ medicinale ${ }^{9}$ et perfeci ipsum die jovis $\mathrm{XI}^{\mathrm{m}}$ die julii anno ab incarnati verbi misterio $\mathrm{M}^{\circ}{ }^{\mathrm{CCCC}} .^{\circ}$ Nonagesimo secundo. Deo gracias I Ffacto fine pia laudetur virgo Maria. Ffinito libro sit laus et gloria Christo. Amen. Laus tibi ${ }^{10}$ sit Christe quem liber explicit iste.

És ben probable que aquest copista formés part de la coneguda família dels Marquet, navegants i almiralls barcelonins. Galceran és un nom habitual al llinatge. Alhora, però, es fa molt difícil identificar-lo amb cap dels Galcerans Marquet esmentats a la documentació coetània conservada. Partint de la datació de la còpia, podria ser el Galceran Marquet que el mateix 1392 consta com a candidat a conseller del Consell de Cent. Malgrat tot, no es pot descartar que es tractés d'un homònim seu, potser d'una branca secundària de la família, atesa la feina de copista en què el documentem ${ }^{11}$.

La mà de Marquet és la responsable de la majoria de textos que hi ha al còdex fins al colofó, inclòs el Tresor de pobres, que hi ocupa els ff. 4ra$54 \mathrm{vb}$. Entre els fulls que va escriure, en va deixar diversos en blanc, especialment just després del final del Tresor, en els quals mans posteriors van recollir nous textos, la majoria receptes.

Partint del recompte d'Asunción Escudero, que va transcriure el text del Tresor, l'obra consta de 215 receptes, o conjunts de receptes, que foren les copiades per Galceran Marquet. A aquestes se n'hi han d'afegir onze més, fins a 226, en els folis deixats a continuació en blanc, fins al f. 57va ${ }^{12}$. De tot

\footnotetext{
8 "volumen": a continuació "et per f", ratllat.

9 "medicinale": corr. "medicinalis".

10 "tibi": amb titlla supèrflua.

${ }^{11}$ Per al coneixement de la família Marquet, és imprescindible Ferrer 2007; per al Galceran Marquet candidat a conseller, esp. p. 224.

${ }^{12}$ El recompte d'Escudero dels capítols del Tresor del ms. 864 hauria de ser confirmat. La investigadora dóna la xifra global de 226 receptes, però no detalla clarament el nombre de les que conformen cadascuna de les agrupacions que hi detecta. Per a l'objectiu del present estudi,
} 
el conjunt, únicament les 109 primeres receptes formarien stricto sensu el Thesaurus pauperum (ff. 6ra-41vb) ${ }^{13}$. Les receptes posteriors, de la 110 a la 226, constitueixen diverses col-leccions afegides després de la composició del recull. Ara bé, això no significa que les 109 receptes inicials es deguin totes, ni molt menys, a la intervenció del futur Joan XXI -si és que ell en va ser el responsable-. Només una cinquantena provindria, segons sembla, del nucli original ${ }^{14}$. La resta de receptes són afegits ulteriors aliens a la col·lecció recollida pel seu primer compilador.

A partir de la 109, es poden identificar quatre grups diferents de receptes. En primer lloc, les que formen el Llibre dels ungüents de Tederic (caps. 110-143; ff. 41vb-46ra), segurament vinculables a la Cirurgia de Teodoric de Borgognoni, i les del Llibre de les pólvores (caps. 144-151; ff. 46ra-47rb), seguides d'una vintena de receptes esparses (caps. 152172; ff. 47va-50rb). Aquests tres grups, que, amb les receptes afegides al nucli del Thesaurus, constitueixen els coneguts com a capitula subditia de la tradició de l'obra, haurien estat incorporats a continuació del llibre en un moment en què segurament ja havia doblat la seva extensió original, de la cinquantena al centenar, amb variants segons els testimonis consultats. Totes aquestes addicions s'haurien produït en una data bastant primerenca, o si més no encara en el curs de la transmissió en llatí. I és des d'aquesta llengua que, com a part integrant de l'obra atribuïda a Pere Hispà, haurien estat transvasades al català.

Al ms. 864 encara hi ha un quart i darrer grup de receptes afegides, format pels caps. 173-226, que no ha estat documentat en testimonis llatins de l'obra. Una part d'aquestes preparacions, la que ocupa els ff. 50va-54vb, és transcrita per Galceran Marquet. A continuació, en els tres folis deixats en blanc pel copista (55ra-57vb), mans posteriors van consignar-hi noves receptes, i alguna prova de ploma, evidentment del tot alienes, si més no

tanmateix, permet disposar d'una orientació sobre el procés d'elaboració del recull i les etapes per les quals va passar.

${ }^{13}$ Per al contingut del Tresor del ms. 864, és útil tenir en compte les consideracions que Asunción Escudero va recollir a la seva tesi doctoral, Escudero 1993, pp. 403-437; per a la numeració de les receptes, parteixo de l'índex de contingut del manuscrit que va elaborar, ibídem pp. 417-432.

${ }^{14}$ Maria Helena da Rocha Pereira, editora del text llatí, remarca que al ms. Add. 22.636 del British Museum, un dels més reculats de què disposa, després de quaranta-set capítols, hi consta l'èxplicit del text, per bé que a continuació s'inclouen altres receptes que, majoritàriament, retroba integrades dins de l'obra en manuscrits posteriors; diversos manuscrits del Thesaurus presenten èxplicits $i$ altres indicis que apunten que el nombre de receptes original s'ha vist generosament ampliat, Pereira 1973, esp. pp. 5-11, 53-55, 66-67. L'editora remarca, això no obstant, que les seves conclusions "não têm ainda carácter definitivo, por se basear em apenas numa parte da tradição manuscrita existente", és a dir, els vint-i-quatre testimonis conservats entre la British Library i la Bodleian, que va tenir ocasió d'estudiar, ibídem, p. 11. 
fins aleshores, a la tradició del Thesaurus. Entre els textos afegits per mans posteriors s'ha d'esmentar una oració a santa Apol·lònia (en l'espai en blanc deixat a la segona columna del f. 54v), per al mal de queixals; una extensa confecció, de la qual es detallen fins a dinou virtuts i utilitats (ff. 55ra-56ra), i quatre altres receptes de mans diferents (f. 56ra-v; la quarta és escrita al verso del foli a ratlla tirada); finalment, hi trobem el pròleg i una desena de capítols del Flors del tresor de beutat, receptari mèdic dedicat a la cura del cos femení (de nou, escrits a doble columna; ff. 56va-57va) ${ }^{15}$. La inclusió del pròleg distingeix el Flors de la resta de la compilació, per bé que no s'ha de perdre de vista que és precisament el fet que es tracti de receptes el que va afavorir que fos copiat en aquest lloc. No és sobrer observar que la mà del XVI que va copiar els passatges del Flors sembla la mateixa que va transcriure la versió castellana del Tractat de les mules de Manuel Dies que trobem no gaires folis més endavant, als 97ra-108va, just després del colofó de Galceran Marquet. ${ }^{16}$

Representat esquemàticament, el contingut de la col·lecció dels ff. $6 r-57 v$ del ms. 864 és el següent:

1. Pere Hispà, Tresor de pobres, amb intercalació de receptes posteriors a l'autor (caps. 1-109; ff. 6ra-41vb).

2. Llibre dels ungüents de Tederic (caps. 110-143; ff. 41vb-46ra).

3. Llibre de les pólvores (caps. 144-151; ff. 46ra-47rb).

4. Receptes esparses (caps. 152-172; ff. 47va-50rb).

5. Conjunt de receptes alienes a la tradició llatina (caps. 173-226):

5.1. Receptes, transcrites per Galceran Marquet (ff. 50va-54vb).

5.2. Afegits de mans posteriors en folis deixats en blanc per Marquet $(54 \mathrm{vb}-57 \mathrm{vb})$ :

5.2.1. Oració a santa Apol-lònia (f. 54vb).

5.2.2. Confecció amb dinou virtuts i utilitats (ff. 55ra56ra).

5.2.3. Quatre receptes de mans diferents (f. 56ra-v).

5.2.4. Flors del tresor de beutat, pròleg i deu capítols (ff. 56va-57va).

\footnotetext{
${ }^{15}$ Vegeu Avenoza 1992. Es tracta d'una versió fragmentària de l'obra, de la qual només es coneix un altre testimoni, copiat al ms. 68 de la Biblioteca de la Universitat de Barcelona; vegeu Santanach 2006, esp. pp. 256-257, n. 40.

${ }^{16}$ Per a la versió castellana del Tractat de les mules, vegeu Riera 1989, p. 706.
} 
Les receptes transcrites pel copista barceloní als ff. 50va-54vb constitueixen la innovació més destacable que presenta aquesta versió del Tresor de pobres respecte de la tradició precedent, per bé que devien ser percebudes pels seus lectors, i molt probablement també pel mateix copista, com a parts integrants de l'obra. De la mateixa manera que això s'esdevenia respecte als capitula subditia.

Sobre el Tresor de la Biblioteca de Catalunya encara s'ha d'esmentar, en una mostra més de la dinàmica que afavoria la reelaboració constant dels receptaris, que no sols es van aprofitar els folis deixats en blanc per afegir-hi noves receptes i altres textos, sinó que unes quantes mans, diferents de la del copista, van recollir als marges dels folis del volum un nombre elevat de preparacions i apunts. Les receptes marginals $i$ els textos afegits als folis deixats en blanc per Marquet són intervencions que, al seu torn, si aquest còdex hagués servit de model per a la còpia d'un nou testimoni, amb tota certesa hi haurien estat incorporades sense cap indicació que permetés a un lector del nou volum constatar que es tractava d'aportacions recents; aleshores aquest hipotètic lector no hauria tingut elements per saber que eren addicions que s'havien produït tot just en l'antecedent del còdex que tenia a les mans, i que de cap manera no provenien de la compilació original ni havien format part de la tradició anterior. Tal com degué passar amb unes quantes de les receptes que actualment conformen el Tresor de pobres del ms. 864.

\section{UNA COL·LECCIÓ UNITÀRIA O COMPOSTA?}

El fet que el Tresor de pobres estigui compost per diverses agrupacions de receptes no pressuposa que els seus lectors, ni els seus copistes, el veiessin com un conglomerat d'obres independents. Al manuscrit es poden localitzar algunes indicacions -gairebé diria reminiscències-que remeten al caràcter autònom d'alguns dels textos que componen el Tresor i que revelen, doncs, la naturalesa composta de la col·lecció. Tanmateix, la majoria d'indicis que ens parlen de la percepció que els usuaris tenien del conjunt es decanten sobretot vers el seu caràcter unitari.

En primer lloc cal fer referència a la taula de rúbriques. $\mathrm{Al} \mathrm{f.} 4 \mathrm{ra}$, en el breu íncipit, invocació inclosa, que obre la taula, llegim: En nom del Para e del Fill e del Sant Sperit, açò és la taula del libre de medicina e de cirugia, lo qual és appellat thesaurus pauperum. Deo gratias.

A continuació, a la taula es recullen les rúbriques de les receptes contingudes als ff. 6ra-54ra, sense cap distinció ni epígraf que assenyali que formen part de col-leccions autònomes o, encara menys, que tenen orígens 
diferents. Tampoc no s'hi inclou cap mena d'informació sobre la resta d'obres contingudes al volum, ni dels folis precedents -una de les quals, dedicada als quatre humors, als ff. 1ra-2rb, va ser copiada per la mà de Galceran Marquetni dels folis posteriors fins al 96ra -majoritàriament també degudes al mateix copista-. La taula recull estrictament, per tant, tal com se'ns indica, el contingut del llibre appellat thesaurus pauperum.

La manca de distinció entre col-leccions a la taula no impedeix, en canvi, com apuntava, que al cos del manuscrit hi hagi algunes indicacions que permeten intuir una certa distinció entre agrupacions. Així, tot i que després del cap. 109 del Tresor no hi ha cap èxplicit, sí que hi trobem l'íncipit del Llibre dels ungüents (Ací començen los ungüents del libre de tederich / e és molt bo a ssanar nafres e a fich e a fístola e a cranch, escrit amb tinta vermella); presenta així mateix un íncipit el Llibre de les pólvores, tot i que és molt menys explícit i es pot confondre fàcilment amb altres epígrafs que agrupen diversos capítols (Ací començen les pólvores, també escrit amb tinta vermella). Al final d'aquest llibre, en canvi, no hi ha cap indicació que assenyali que s'ha acabat ni que remarqui que a continuació hi ha un conjunt de receptes que ja no en forma part. Finalment, després de la recepta 172, al f. 50rbva, hi ha l'èxplicit següent, escrit amb la mateixa tinta negra que el cos del text (amb la vermella sols s'ha elaborat la caplletra amb què s'inicia el segon paràgraf $i$ algun altre detall ornamental):

Hic finitur compendium istud etcetera.

Entrò açí lo trebayll de la fi d'aquest libre és acabat. D'aquí avant, senyor Jhesucrist, tu qui es vertadera salut de totes coses, dóna a mi, servent, de trebayllar volentat en aquesta obra e poder de acabar a la tua honor e al profit comunal, e majorment al profit dels teus pobres. Tu, senyor Jhesucrist, guarda mi e aquest libre de falçaris e de males gents. Et endreça tots aquells qui feelment requeren ne demanen aquests remeys ${ }^{17}$ e il-lumina I aquells en la conaxença d'aquestes coses qui en aquest libre són contengudes, en tal manera que puxen profitar e haver remey dels trebaylls e consolació bona. Qui vivis et regnas in unitate Spiritus Sancti Deus per omnia secula seculorum amen.

És sens dubte remarcable que, al mateix temps que s'afirma que s'ha enllestit lo trebayll -per la còpia- del compendi, es demani d'aquí avant voluntat i forces per treballar en aquesta obra i acabar-la. L'aparent contradicció pot explicar-se si es planteja que l'èxplicit deu ser, molt probablement, resultat de dues intervencions diferents, produïdes en antecedents del ms. 864: la d'un

17 “remeys": amb titlla supèrflua. 
primer copista que, efectivament, tancava aquí la compilació (considerada de nou, per cert, com una unitat), i un segon que constatava que encara quedava feina pendent abans de poder donar per acabada l'obra.

Les receptes que hi ha a continuació dels capitula subditia no presenten, més enllà de l'èxplicit esmentat, un tant confusionari, cap indicació que les distingeixi de la resta de capítols que integren aquesta versió de l'obra. Tampoc a la taula de rúbriques que obre el Tresor no hi ha cap epígraf que les individualitzi, com s'ha assenyalat.

En conseqüència, a part de l'íncipit del Llibre de les pólvores (f. 46ra), al qual el copista ha donat un tractament equivalent a epígrafs d'altres apartats del text, l'única veritable indicació que revela la incorporació d'una col·lecció prèviament independent és l'íncipit del Llibre dels ungüents (f. 41vb). I, és clar, tot i el seu caràcter un pèl confús, l'èxplicit del f. 50rb-va, situat entre els capitula subditia i les receptes no documentades dins la tradició llatina.

\section{DIVERGÈNCIES ENTRE LA TAULA DE RÚBRIQUES I LA COL·LECCIÓ RECOLLIDA AL MANUSCRIT}

A la taula de rúbriques dels ff. 4r-5v s'esmenten les receptes de tradició llatina -el nucli originari de Pere Hispà i els capitula subditia-,i també part dels afegits posteriors. És a dir, a grans trets conté les rúbriques de la col·lecció copiada per Galceran Marquet, que és igualment qui va transcriure la taula. Però ho fa de forma parcial i amb divergències significatives. I és que tot sembla indicar que Marquet es va limitar a copiar la taula tal com l'havia rebut del seu antígraf, sense comprovar si les entrades es corresponien pròpiament amb el contingut del llibre.

D'acord amb les apreciacions d'Escudero ${ }^{18}$, de les 199 rúbriques de receptes que es recullen a la taula inicial, les quals no són numerades al manuscrit, n'hi ha 21 que manquen al cos del text. La seva desaparició no va ser causada per cap accident material del ms. 864, com fóra el cas de la pèrdua d'un quadern, ja que no són receptes consecutives. Es tracta, més aviat, d'omissions, fortuïtes o deliberades, produïdes durant el procés de còpia del text, ja fos en el còdex de la Biblioteca de Catalunya o ja fos, més aviat, en antecedents seus. Les entrades corresponents de la taula constitueixen, per tant, l'única documentació que tenim de la seva existència.

Contràriament, no consten a la taula de rúbriques 48 de les receptes que sí que formen part de la col·lecció. Aquest fet és esperable respecte a les entrades

${ }^{18}$ Escudero 1993, pp. 403-434. 
216-226, escrites per mans diferents de la de Galceran Marquet; no n'és tant, en canvi, que hi manquin una quarantena de receptes que aquest amanuense sí que va copiar. Tot sembla indicar, per tant, que van ser afegides al recull després de l'elaboració de la taula original -de la qual l'índex que hi ha als ff. 4r-5v del ms. 864 és sols una còpia-. És possible que, en copiar la taula, s'ometés alguna rúbrica per descuit, i més tenint en compte que no estan numerades, però que se'n perdessin gairebé quaranta és excessiu. Sembla bastant més factible que aquestes receptes siguin addicions més recents. Tot plegat significa que, partint d'una versió, segurament ja traduïda al català, que contenia unes dues-centes receptes, tal com assenyala la taula de rúbriques, el conjunt de textos que conformen el Tresor de pobres va patir una seixantena de canvis, entre omissions i afegits de receptes. Això, sense comptar les onze addicions posteriors a l'any 1392.

Tenint en compte l'abast dels canvis assenyalats entre el contingut del Tresor i la taula de rúbriques que el precedeix, elaborada per a un antecedent perdut del ms. 864, aquest antecedent difícilment podria haver estat l'antígraf -el seu model immediat- del còdex de la Biblioteca de Catalunya. Sense descartar aquesta possibilitat, sembla molt més probable que el cúmul de modificacions no es produís d'un sol cop, sinó al llarg de diversos trasllats de la col·lecció. L'antecedent que reflecteix la taula de rúbriques, per tant, deu ser bastant més reculat. Cosa que implica que bona part de les receptes afegides deuen haver tingut una relació amb la tradició del Tresor de pobres que passa per diverses còpies de l'obra.

\section{EL CONJUNT DE RECEPTES NO DOCUMENTADES A LA TRADICIÓ LLATINA}

Les receptes alienes a la tradició llatina del Tresor de pobres, però que van ser transcrites pel copista Galceran Marquet als ff. 50va-54vb del còdex, són en bona part esmentades a la taula de rúbriques inicial. La darrera que s'hi recull es troba al f. 54ra, mentre que la intervenció del copista barceloní s'allarga tot just fins al verso d'aquest mateix foli. Són majoritàriament preparacions destinades a guarir dolències, cosa que coincideix plenament amb el caràcter i el contingut de l'obra. Asunción Escudero va optar per no transcriure-les en el seu estudi precisament perquè, a diferència de les receptes que les precedien, no formaven part de la tradició documentada del Thesaurus pauperum. I és ben cert que no disposem de cap evidència que les relacioni amb aquest títol prèviament a la seva presència al còdex de la Biblioteca de Catalunya ${ }^{19}$.

\footnotetext{
${ }^{19}$ Sobre aquestes receptes, incloses les que arriben fins al f. 57v, Escudero observa que es tracta d'apartats afegits a "la obra original y no forman parte del texto", i que, contràriament als capitula subditia, "la mayoría de estos capítulos son de una receta y de carácter marcadamente
} 
Es tracta de receptes que, previsiblement, tenen orígens diversos i que es deguen incorporar de mica en mica, potser en còpies successives, al receptari prèviament constituït, de la mateixa manera que al final del Tresor del ms. 864 mans posteriors van recollir-hi textos provinents, com a mínim, de tres fonts diferents -l'oració a santa Apol-lònia, les receptes esparses i els passatges del Flors del tresor de beutat-. També en aquesta qüestió resulta de nou il-lustradora la comparació amb el Llibre de Sent Soví de la Universitat de València. Al final d'aquest tractat de cuina, després de les receptes documentades en la tradició textual prèvia, n'hi ha encara catorze que són, sense cap mena de dubte, fruit d'incorporacions posteriors, atès que no són esmentades a la taula de rúbriques inicial. Podria tractar-se, és clar, d'un recull unitari $-\mathrm{o}$, almenys, amb una certa circulació unitària prèvia- que hagués estat incorporat conjuntament al final del Sent Soví; el fet, però, que una, i només una, d'aquestes receptes es pugui documentar aïlladament de la resta, dóna pes a la possibilitat que es tracti d'addicions més o menys autònomes les unes de les altres. Cosa que no exclou, és clar, que entre elles hi pugui haver hagut alguna agrupació parcial, anterior a la seva incorporació al final del Sent Sovi ${ }^{20}$.

La situació del ms. 864 és bastant similar. I és que no sembla gaire probable que les receptes que hi ha a continuació dels apartats provinents de la tradició llatina del Tresor, em refereixo a les copiades per la mà de Galceran Marquet, comparteixin totes un mateix origen. Sí que podem pressuposar, en canvi, vinculacions prèvies entre alguns conjunts que s'hi detecten. És el cas d'un grup de preparacions de confits, que ja devien haver estat agrupades abans de la seva incorporació entre les receptes finals del Tresor. Sense que puguem descartar, és clar, que haguessin estat incorporades al volum com a anotacions independents. Sigui com sigui, la presència d'aquesta mena d'elaboracions dolces en un volum de contingut eminentment mèdic no és de cap manera excepcional, perquè sovint eren recollides per apotecaris i usades amb finalitats terapèutiques. Això no impedia que fossin així mateix consumides com a llepolies.

El fet que els confits estiguin agrupats en mig de receptes que no mostren cap organització temàtica evident, també fa versemblant que haguessin constituït una certa unitat abans de la seva incorporació al Tresor. Hauria estat, per tant, com a conjunt, i no com a unitats esparses, que haurien passat a formar part del recull, al costat d'altres addicions. Dóna suport a aquesta possibilitat que els procediments d'elaboració de les tres primeres preparacions de confits (taronjat, poncemat i pastanagat) siguin molt similars, i també que a la recepta

popular, fuera del desarrollo normal de las recetas contenidas en el «Tresor dels pobres»", ibidem, p. 434.

${ }^{20}$ La recepta LXIV del Sent Soví comparteix una mateixa font amb la 41 del Llibre d'aparellar de menjar; vegeu Santanach 2010, p. 366. 
de pastanagat es remeti a la de poncemat que la precedeix (s'hi aconsella remenar la pasta de pastanaga fins que sigui cuita axí com lo ponçemat). Hi ha així mateix alguns indicis, encara que més tènues, que vinculen les altres dues receptes, de pinyonat i sobre la cocció del sucre, tal com s'indica a l'apartat següent.

És igualment possible que tinguin un origen comú, per bé que independent de les preparacions de confits, dues receptes atribuïdes a mestre Arnau de Vilanova copiades també al final del Tresor. Es tracta de receptes $a$ sanar mala busanya (f. 51va) i per mal de vexiga e de pedra (f. 52va-b) ${ }^{21}$, a l'inici de les quals s'esmenta el nom del famós metge. Atès que es tracta de receptes no copiades de forma consecutiva, sinó integrades entre altres preparacions mèdiques, no es pot descartar que alguna altra de les receptes del conjunt comparteixi amb aquestes dues una mateixa procedència, malgrat que no s'hi esmenti el nom de mestre Arnau.

Hi ha, encara, un darrer grup de receptes, les 207-214 (ff. 53vb-54ra), escrites en llatí, susceptibles d'haver constituït una col-lecció prèvia a la seva incorporació al recull. Les coincidències de contingut i lingüístiques, i la mateixa agrupació i contigüitat, hi donen suport. La presència d'aquestes receptes entre les no documentades dins la tradició llatina del Tresor, d'altra banda, dóna paradoxalment consistència a la hipòtesi que, si més no una part de les addicions posteriors a la recepta 172 , hi va ser afegida una vegada el Thesaurus ja havia estat traduït al català. Altrament, aquestes receptes en llatí haurien estat així mateix traslladades a la llengua vulgar.

\section{LES RECEPTES DE CONFITS}

Entre els llibres de cuina medievals, els reculls de confits constituïen un grup específic, dedicats sobretot a la preparació de fruita confitada i melmelades, per bé que de vegades també hi localitzem altres tipus de receptes dolces. En català n'hem conservat dos de diferents. El Llibre de totes maneres de confits, al ms. 68 de la Biblioteca de la Universitat de Barcelona, compost per trenta-tres receptes, i la Recepta de la bona composta, al ms. 6437 de la Biblioteca Serrano Morales de València, formada no sols per l'extensa recepta inicial que li dóna nom, sinó també per tres preparacions més. ${ }^{22}$

\footnotetext{
${ }^{21} \mathrm{Hi}$ ha una recepta similar a la darrera, malgrat que amb una redacció diferent, en el Regiment de sanitat adreçat a Jaume II, Vilanova 1947, vol. II, p. 140. Per a la presència de receptes esparses atribuïdes a mestre Arnau, d'autenticitat encara per confirmar, vegeu Cifuentes 2011-2013.

${ }^{22}$ Vegeu Santanach 2003; en premsa. En el primer dels estudis citats es remet a altres reculls de confits sorgits en contextos propers, que ajuden a contextualitzar la producció escrita en català.
} 
Pel que fa al ms. 864, el conjunt de receptes de confits que comparteixen versemblantment una font comuna està actualment format per quatre preparacions, tres de les quals són melmelades fetes amb xarop de mel (taronjat, poncemat, pastanagat), i la quarta és d'un torró de pinyons (el pinyonat), elaborat amb sucre. A aquestes receptes cal afegir-ne una cinquena que, de fet, constitueix una recomanació per conèixer si el sucre, probablement el que s'ha emprat a la recepta anterior, la de pinyonat, ha arribat al punt de cocció necessari per elaborar el plat. Les cinc receptes són copiades consecutivament als ff. 51vb-52va del còdex ${ }^{23}$. Els indicis que hi ha sobre un origen comú previ a la seva incorporació al Tresor apunten, doncs, amb totes les precaucions que calgui, vers l'existència d'una col·lecció de confits fins ara desconeguda, de la qual no ens ha arribat altra notícia que la inclusió de receptes que en provindrien en la col·lecció originària de Pere Hispà.

Si assumim com a possible aquesta hipòtesi, també hauríem de considerar que hauria format part del grup una sisena recepta, incorporada al Tresor juntament amb la resta; més endavant, en el curs de la transmissió de l'obra, n'hauria estat omesa, com tantes altres preparacions. En efecte, trobem que a la taula de rúbriques inicial no sols s'hi van consignar les cinc receptes conservades, sinó també aquesta sisena, que les precedia (f. 5vb). Hi llegim les entrades següents:

Si vols fer nous confites

Si vols fer torongat

Si vols fer poncemat

Lij

Lij

Si vols fer pestenagat

Si vols fer pinyonat

Si vols haver conaxença del cucre con deu ésser cuyt a perfectió
$\mathrm{Lij}$

Lij

Lij

La primera entrada, la recepta de nous confites, és la que no s'ha conservat al manuscrit de la Biblioteca de Catalunya ${ }^{24}$. L'esment a la taula, tanmateix, assenyala que sí que degué formar part d'un antecedent seu. L'hipotètic conjunt de confits del recull, per tant, hauria estat compost almenys per sis receptes ${ }^{25}$. Pel que fa a la taula, cal remarcar que un lector medieval del còdex es va sentir especialment interessat per aquestes preparacions de confits, com indica el fet que al costat de cadascuna de les cinc receptes

\footnotetext{
${ }^{23}$ Constitueixen les receptes 191-195 d'acord amb el recompte d'Escudero 1993, p. 429.

${ }^{24}$ Documentem receptes de nous confites, també anomenades nous verdes, en diversos receptaris catalans -al Llibre de Sent Soví, al Llibre d'aparellar de menjar o al Llibre de totes maneres de confits-, com també en altres llibres de cuina europeus; vegeu Santanach 2003, pp. 282-283, n. 1 .

${ }^{25}$ Constitueixen les entrades 181-186 de la numeració amb què A. Escudero va distingir les rúbriques de la taula inicial, Escudero 1993.
} 
que es conserven al recull -i no, en canvi, al de l'omesa dedicada a les nous confites-, hi va assenyalar el foli ("LII") on es troben. Es tracta d'una mà clarament diferent de la del copista de la col-lecció i responsable de la taula de rúbriques, el repetidament esmentat Galceran Marquet. Altres usuaris van escriure indicacions similars al costat d'altres entrades de la taula, però la mà del que va interessar-se per les receptes de confits no l'hi tornem a trobar.

Les tres primeres receptes presenten similituds, com s'ha dit, pel que fa a l'elaboració dels confits que descriuen. Tots tres casos exposen preparacions de melmelada -és a dir, preparacions en què l'ingredient principal és picat, no pas confitat sencer o tallat a bocins-, en les quals la fruita, una vegada picada, es bull i s'escorre repetidament, i en què s'empra com a element endolcidor, conservant i aglutinador un xarop preparat amb mel.

L'elaboració i el resultat de la segona recepta, la de poncemat, és molt semblant al del Poncem ras inclòs com a cap. VII del Llibre de totes maneres de confits; el procés d'elaboració recorda igualment el seu cap. I, Per confegir ponsemps, tot i que en divergeix pel fet que els poncems no es piquen, sinó que se'n fan tallades. La recepta de pastanagat en recorda igualment una altra del mateix llibre, al cap. X, Per confegir bestonagues, encara que en aquesta ocasió, de nou, les pastanagues es tallen a bocins i no s'hi indica que s'hagin de triturar. En canvi, a la recepta que hi ha al Llibre de confits per fer taronges confitades amb mel (cap. IV), els cítrics, que es recomana que siguin de dimensions reduïdes, es preparen sencers i se'ls practiquen petites incisions per tal de poder-los farcir amb gingebre i claus d'espècia ${ }^{26}$.

Pel que fa a la recepta de pinyonat, de vegades també anomenat pinyonada, es tracta d'una elaboració feta bàsicament amb la fruita seca que li dóna nom i, en aquesta ocasió, sucre, no pas mel, als quals s'afegeix gingebre en pols. Amb el sucre fos, s'hi tiren els pinyons i, mentre encara és calent, s'estén la barreja sobre una taula i se'n fan porcions, tal com s'indica en una recepta similar, tot i que bastant més explícita, al cap. XIX del Llibre de confits $^{27}$.

La relació de la recepta de pinyonat amb la que la segueix, en què es dóna una indicació per conèixer el moment en què el sucre que s'hi ha d'usar està al seu punt just de cocció, és ben evident. No sols per la seva utilitat en la recepta de pinyonat, sinó també per la quantitat de sucre esmentada -una lliura-i per la coincidència respecte de la proporció d'aigua que s'hi ha d'usar -la mateixa que de sucre-. Aquestes dues receptes, tot i els punts de contacte, en constitueixen dues d'independents al recull del ms. 864: malgrat que la

\footnotetext{
${ }^{26}$ Vegeu Santanach 2003.

${ }^{27}$ Ibidem, pp. 286-288. Al mateix text hi ha una altra preparació de pinyonada, al cap. XXXI, d'elaboració una mica més complexa i feta amb mel.
} 
darrera no té rúbrica pròpia al f. 52rb, és inclosa a la taula inicial, en què es llegeix clarament que és útil Si vols haver conaxença del cucre con deu ésser cuyt a perfectió; a més, s'obre, com la resta de receptes, amb una caplletra escrita amb tinta vermella, que fa la funció d'assenyalar la condició d'apartat independent de la recepta. No es pot descartar, és clar, que en origen n'haguessin format una de sola, com tampoc que un lector de la recepta de pinyonat, davant d'una redacció tan concisa, hagués considerat útil afegir-hi la indicació sobre el sucre i ho hagués fet al marge del seu manuscrit.

\section{EDICIÓ DE LES RECEPTES DE CONFITS}

Transcric a continuació el text de les cinc receptes copiades als ff. 51vb-52va del ms. 864 de la Biblioteca de Catalunya, únic testimoni conegut d'aquest conjunt. Seguint els criteris de la col-lecció Els Nostres Clàssics (Editorial Barcino), he respectat fidelment l'ortografia del manuscrit, i només he regularitzat l'ús de majúscules i minúscules, el de $u \mathrm{i} v$, i el de $i$ i $j$. He accentuat els mots i m'he servit de l'apòstrof i del guionet d'acord amb la normativa del català actual. Per a les elisions que avui no tenen representació gràfica, he utilitzat el punt volat. Així mateix, he separat o aglutinat els mots segons la normativa. He puntuat el text d'acord amb la lectura que m'ha semblat més adequada.

A les notes consigno les lliçons rebutjades del manuscrit, i les incidències del testimoni que em semblen dignes de remarca.

[RECEPTES DE CONFITS DEL TRESOR DE POBRES]

$[51 \mathrm{vb}][\ldots]$

\section{[1.] SI VOLETS FER TARONGAT ${ }^{28}$ [52ra]}

Prenets de les taronges e levats les escorxes e tayllats-les bé menut. Puys perbullits-les en aygua bona e dolça. Et puys enaprés, quant seran perbullides, gitats-les en aygua freda e dolça, e stien $I^{\mathrm{a}}$ nit. Puys premets-les bé de l'aygua. Puys bollits-les en aygua un poch, en la qual aygua age I poch de mel. Puys trets-les d'aquella aygua e premets-les bé e picats-les. E après pessats-ho e metets a $\mathrm{I}^{\mathrm{a}}$ libra ${ }^{29}$ de les taronges $\mathrm{II}^{\mathrm{es}}$ libras de bona mel. E puys sia cuyt

\footnotetext{
${ }^{28}$ Les rúbriques són escrites en vermell; a continuació d'aquesta, que es troba al final de la segona columna del f. 51v, una mà posterior va escriure una recepta de "tinta bona", ja al marge inferior de la segona columna, fora de caixa.

29 "libra": desenvolupo aquest mot, que apareix diverses vegades abreviat als passatges seleccionats, com a libra o lliura segons si al text manuscrit trobem "lbra" o "llra", respectivament.
} 
a perfectió. E metets a cada libra del confit ${ }^{30}$ mige onza de gingebre bé picat con sia I poch oreyat.

\section{[2.] SI VOLETS FER PONÇEMAT}

Prenets los ponçems e fenets-los per mig e trets-ne lo cor. E puys rellats-los $a b$ una raadora de ferre. E remuyllats-los en aygua per $I^{\mathrm{a}}$ nit, e en l'endemà premets-los bé, que n'isqua l'aygua. Et pesats-ho, e metets en $\mathrm{I}^{\mathrm{a}}$ libra de la pasta dels ponçems II lliures ${ }^{31}$ e mige de mel. E coga tot ensemps tota hora bé menant e cohetsho a perfectió. E con volrets veer si és cuyt, prenets-ne I poch e posats-ho sobre I coltel; e con serà dur que's tengua serà cuyt. Puys levats-ho del foch e metets-hi ${ }^{32}$ a IIII libres de confits ${ }^{a}$ onza de gingebre ben picat, e sia bé encorporat, tota via [52rb] ben menant.

\section{[3.] SI VOLETS FER PASTANEGAT}

Prenets de les pastenagues blanques e fets-ne troços. E coets-les en aygua en guisa que sien bé blanques. $\mathrm{E}^{33}$ puys sien bé picades en I morter. Puys pesats-ho e a cada lliura de pastenagues metets $\mathrm{I}^{\mathrm{a}}$ libra de mel. E coga bé menant tota hora, tro sia cuyt axí con lo ponçemat. E metets en II libres dels confits I onza de gingebre picat. E sia bé picat.

\section{[4.] SI VOLETS FER PINYONAT}

Prenets pinyons mundats $\mathrm{I}^{\mathrm{a}}$ lliura e $\mathrm{I}^{\mathrm{a}}$ lliura de sucre. E coets lo sucre ab una libra d'aygua fins que l'aygua sia consumada. Puys levats-ho del foch et mesclats-hi los pinyons menant; e sia-hi tanbé $^{34}$ mesclat mige onza de gingebre bé picat.

\section{[5. PER HAVER CONEIXENÇA DEL SUCRE, QUAN DEU ÉSSER CUIT A PERFECCIÓ]}

Si volets haver conaxença del sucre con deu ésser cuyt a perfectió, metets I ${ }^{\mathrm{a}}$ lliura de sucre ab I $\mathrm{I}^{\mathrm{a}}$ lliura d'aygua en la caça, e bulla sobre 1 foch de carbó o de lenya secha ab petit foch. E con haurà $\mathrm{I}^{\mathrm{a}}$ peça bullit, que començarà a espessir, menats-la bé ab la spàtula. E si hi à aygua perdrà la bullidura e tornarà clar, e lexats-lo bollir. Mas regonexets-lo altra vegada, e a cap de $\mathrm{I}^{\mathrm{a}}$ peça, con veurets que bullirà espès, regalats-ne [52va] ab la spàtula; si fa fils, que·s tinga, deu ésser cuyt. E prenets-ne d'aquell qui·s té en la spàtula

\footnotetext{
30 "confit": al ms. "confits".

31 "lliures": a continuació, al ms. hi ha "de" expuntuat.

32 "metets-hi": la primera "e" corregeix una "i" llarga.

33 "E": al ms. segueix "fets ne troços", expuntuat, i "troços" ratllat amb el mateix roig que les rúbriques.

34 "tanbé": al ms. damunt la "n" hi ha una titlla supèrflua ratllada.
} 
ab II dits, si·s té, e con se tindrà que farà fils és cuyt; e con lo menereu entre los dits, si fa redulí és cuyt.

\section{CONCLUSIONS}

Els receptaris medievals de contingut pràctic que ens han arribat, siguin mèdics, culinaris o de qualsevol altra naturalesa, són molt sovint producte d'un llarg procés d'elaboració, en què usuaris successius han deixant la seva empremta. Testimonis d'un mateix text, llavors, poden presentar importants divergències, depenent del camí que hagin seguit els seus antecedents. Detallar algunes de les etapes per les quals una col·lecció concreta ha passat ens ajuda a valorar millor els materials que la componen.

El Tresor de pobres és un llibre que va tenir una circulació molt àmplia. Intervencions produïdes al llarg d'aquest procés van modificar progressivament el nucli originari de l'obra. L'anàlisi de la versió en llengua catalana copiada al ms. 864 de la Biblioteca de Catalunya posa al descobert alguns indicis d'aquestes modificacions. Alhora, permet constatar que per als copistes, i doncs per als seus usuaris, el text resultant d'aquestes intervencions era percebut com una obra unitària, no pas com un agregat de fonts diverses.

Una part important de les modificacions i ampliacions de què van ser objecte els antecedents del que acabaria sent el Tresor del ms. 864 es van produir durant la transmissió de la versió llatina. Partint de la compilació original, formada per una cinquantena de receptes, usuaris posteriors van ampliar considerablement la col-lecció. Van duplicar el nombre de receptes del recull intercalant-hi noves preparacions, i hi van introduir altres modificacions menors. Contemporàniament, $\mathrm{o}$ en una etapa o etapes poc posteriors, noves intervencions alienes al compilador inicial -fos o no Pere Hispà- van afegir al final del conjunt llatí el Llibre dels ungüents de Tederic, el Llibre de les pólvores i un conjunt de receptes esparses. A continuació aquesta colllecció, que gairebé quadruplicava el nombre inicial de receptes, va ser traduïda a la llengua catalana.

La versió en català, com abans la llatina, va ser objecte de nous canvis i ampliacions. Nous lectors hi van incorporar noves receptes, ja fos intercalant-les entre les que conformaven la col·lecció rebuda, ja fos agrupant-les al final. Entre aquestes darreres, cal comptar-hi almenys un parell de capítols atribuïts a Arnau de Vilanova -al costat d'altres receptes mèdiques en català-; vuit receptes mèdiques més escrites en llatí, i no pas menys de sis preparacions de confits provinents d'un recull innominat, també en català. Va ser, segons tots els indicis, per a aquesta versió del Tresor de pobres que es va elaborar la 
taula de rúbriques dels ff. 4r-5v. La següent etapa documentada ja correspon, pròpiament, a la còpia de l'obra conservada al còdex de la Biblioteca de Catalunya, datada l'any 1392 i obra del copista Galceran Marquet.

La intervenció de Marquet presenta bastants punts en comú amb l'antecedent consignat a la taula de rúbriques. Alhora, però, hi observem algunes divergències remarcables. Així, cal mencionar que al cos del text hi ha una quarantena de receptes no recollides a l'índex, que hem de suposar addicions posteriors a l'antecedent esmentat -l'antecedent per al qual es va preparar la taula-. Entre aquestes, n'hi ha algunes de situades al final del text copiat: mentre que el trasllat de Marquet arriba fins a la segona columna del verso del f. 54, la darrera de les entrades de la taula fa referència a una recepta iniciada a la primera columna del recto del mateix foli. Contràriament a aquestes, que no s'esmenten a l'índex però que podem llegir al cos del llibre, a la taula hi ha una vintena d'entrades referents a receptes que no s'han conservat a l'obra. La colllecció només conté, per exemple, cinc receptes de confits, mentre que a la taula se n'hi esmenten sis.

Aquestes divergències podrien haver estat obra, evidentment, del mateix copista del còdex, Galceran Marquet, que després de transcriure la taula tal com l'havia rebut hauria pogut afegir i eliminar receptes seguint el seu propi criteri. Sembla més versemblant, però, que es tracti de modificacions produïdes per intervencions diferents; és a dir, que es tracti de receptes i anotacions escrites al marge $i$ al final del recull per usuaris diversos, i segurament en còpies diverses, que en trasllats posteriors haurien passat a integrarse al cos del text. Igualment, les supressions haurien estat propiciades per la intervenció de copistes que, per descuit o deliberadament, haurien prescindit de determinades receptes. Un procés d'aquesta mena, producte de diverses còpies amb lleugeres modificacions respecte dels seus immediats precedents, ajuda a explicar que no s'hagués intervingut en la taula de rúbriques. Altrament, si, durant l'elaboració del ms. 864, el copista Marquet hagués dut a terme ell tot sol el conjunt de canvis esmentats, probablement hauria optat per deixar-ne constància a la taula de rúbriques.

Després de l'any 1392 el Tresor de pobres del ms. 864 va continuar sent objecte d'interès per a nous lectors, que, com els seus antecessors, van recollir receptes als marges dels folis del còdex i, també, van aprofitar les pàgines en blanc deixades per Marquet al final de la seva còpia per afegir-hi nous textos, obra de mans diferents de la seva. Entre aquests, l'Oració a santa Apol-lònia, la confecció amb dinou virtuts i utilitats, altres receptes esparses, i el pròleg i deu capítols del Flors del tresor de beutat. Textos que, és clar, ningú no va consignar a la taula de rúbriques.

És només partint d'aquestes constatacions, mal que de vegades merament hipotètiques, que es pot assajar una certa aproximació al camí reco- 
rregut per un receptari medieval fins a assolir la forma amb què ens ha pervingut. Apuntar en quin moment, o potser millor en quina etapa, van entrar a formar-ne part alguns dels components que hi detectem, ens ajuda també a caracteritzar aquests components.

Això és el que s'ha assajat amb les receptes de confits del ms. 864. Els paral-lelismes de contingut i altres punts de contacte que s'observen entre elles fan molt versemblant que comparteixin un mateix origen. Abans de la seva incorporació entre els capítols finals del Tresor de pobres podrien haver format part d'una col·lecció preexistent de confits. Les receptes del còdex constituirien, en conseqüència, l'únic vestigi conservat d'aquesta col·lecció. Parlem d'un recull de preparacions dolces del qual fins ara no teníem notícia, i que se suma, amb les precaucions que calgui, a les altres dues col-leccions medievals d'aquesta mena que s'han conservat en català, els ja esmentats Llibre de confits i la Recepta de la bona composta.

Són ben poques les coses que podem afirmar sobre aquesta hipotètica "nova" col·lecció. No sabem ni tan sols el nom amb què va circular, si és que mai va arribar a tenir-ne cap. I encara menys la seva extensió ni el nombre de receptes que la devien formar; això considerant, és clar, que estava composta per més de les sis receptes que testimonia la taula de rúbriques del ms. 864, cosa que en realitat tampoc no sabem.

Sí que podem apuntar, en canvi, que és ben probable que aquesta collecció fos escrita originalment en català. Al cap i a la fi, les sis receptes -cinc de conservades- es troben entre els textos incorporats al Tresor de pobres una vegada l'original llatí del recull ja havia estat traduït a la llengua catalana. Les receptes de confits, per tant, ja eren escrites en aquesta llengua abans d'entrar a formar-ne part. I atès que no hi ha indicis que fossin traducció de cap altre idioma, cal considerar com a més probable la hipòtesi que haguessin estat redactades directament en català. Amb aquest serien tres, doncs, els receptaris de confits que ens consta que van circular, i probablement van ser escrits, en català a l'edat mitjana.

\section{BIBLIOGRAFIA CITADA}

Alberni, Anna (2006), L'edició en lletra gòtica de l'Speculum al foder (1917). Història d'un misteriós exemplar d'infern, "Llengua \& Literatura" 17, pp. 257-282.

Avenoza i Vera, Gemma (1992), Una còpia desconeguda del Tresor de beutat $i$ altres tractats mèdics, "Boletín Bibliográfico de la Asociación Hispánica de Literatura Medieval” 6/2,pp. 229-236. 
Beaujouan, Guy (1972), Manuscrits médicaux du Moyen Âge conservés en Espagne, "Mélanges de la Casa de Velázquez" 8, pp. 161-221. Ara també dins el seu Science médiévale d'Espagne et d'alentour, Aldershot-Brookfield, Variorum, 1992 (Collected Studies Series; 374), cap. V.

Biblioteca de Catalunya (1923-1927), Adquisicions de manuscrits, "Butlletí de la Biblioteca de Catalunya" 7, pp. 347-355.

BITECA: Bibliografia de textos catalans antics, URL: http://bancroft.berkeley.edu/philobiblon/biteca_en.html [consulta: 18/01/2017].

Cifuentes i Comamala, Lluís (2006), La ciència en català a l'Edat Mitjana $i$ el Renaixement, Barcelona, Universitat de Barcelona - Universitat de les Illes Balears (Col·lecció Blaquerna; 3$)$.

Cifuentes i Comamala, Lluís (2010), Estratègies de transició: pobres i versos en la transmissió extraacadèmica del saber a l'Europa llatina tardomedieval, en Alberni, Anna; Badia, Lola; Cabré, Lluís (eds.), Translatar i transferir: la transmissió dels textos i el saber (12001500), Santa Coloma de Queralt, Obrador Edèndum - Tarragona, Universitat Rovira i Virgili, pp. 241-263.

Cifuentes i Comamala, Lluís (2011-2013), La bibliografia mèdica catalana d'Arnau de Vilanova: estat de la qüestió i nous textos (amb una nota sobre la difusió a Catalunya d'una Vida d'Arnau), "Arxiu de Textos Catalans Antics" 30, pp. 191-238.

Cifuentes i Comamala, Lluís (2013), El manuscrit del receptari de misser Joan, en Mutgé i Vives, Josefina; Salicrú i Lluch, Roser; Vela Aulesa, Carles (eds.), La Corona catalanoaragonesa, l'Islam i el món mediterrani. Estudis d'història medieval en homenatge a la doctora Maria Teresa Ferrer i Mallol, Barcelona, CSIC, Institució Milà i Fontanals, pp. 155-167.

Escudero Mendo, Asunción (1993), Manuscritos de la Biblioteca de Catalunya de interés para la farmacia y las ciencias médicas, en particular el "Tresor dels pobres", Barcelona, Universitat de Barcelona (tesi doctoral inèdita).

Escudero, Asunción; Urbano, María Ángeles; Martín, María José (1992), Estudi farmacològic d'un receptari del segle XV: Receptari de Micer Johan, "Gimbernat. Revista Catalana d'Història de la Medicina i de la Ciència" 18, pp. 43-47.

Ferrer i Mallol, Maria Teresa (2007), Una família de navegants: els Marquet, en Batlle, Carme; Ferrer i Mallol, Maria Teresa, El "Llibre del Consell" de la ciutat de Barcelona, segle XIV: les eleccions municipals, Barcelona, CSIC, Institució Milà i Fontanals, pp. 135-267.

Mateo y Lopis, Felipe (dir.) (1959), Guía de la Biblioteca Central de la Diputación Provincial de Barcelona, Barcelona, Biblioteca Central. 
Massó Torrents, Jaume (1906-1912), Manuscrits catalans de Valencia (Acabament), "Revista de Bibliografia Catalana" 6, pp. 145-269.

MCEM: Base de Dades de Manuscrits Catalans de l'Edat Moderna, URL: http://mcem.iec.cat/entrada.asp?epigraf_m=1 [consulta: 18/01/2017].

Meirinhos, José Francisco (1996), Petrus Hispanus Portugalensis? Elementos para uma diferenciação de autores, "Revista Española de Filosofía Medieval" 3, pp. 51-76.

Meirinhos, José Francisco (2005), O papa João XXI e a ciência do seu tempo, en Cadafaz de Matos, Manuel (coord.), A apologia do latim. In honorem Dr. Miguel Pinto de Meneses (1917-2004), Lisboa, Távola Redonda, vol. I, pp. 129-171.

Meirinhos, José Francisco (2013), O Tesouro dos pobres de Pedro Hispano, entre o século XIII e a edição de Scribonius em 1576, en Cardoso, Adelino; Costa, Julio; Andrade, António Manuel Lopes, Humanismo, Diáspora e Ciência séculos XVI e XVII, Porto, Universidade de Aveiro - Biblioteca Pública Municipal do Porto, pp. 327-350.

Moliné i Brasés, Ernest (1914), Receptari de Micer Johan, "Boletín de la Real Academia de Buenas Letras de Barcelona" 14/54, pp. 321-336, 407440.

Pereira, Maria Helena da Rocha (1973), Obras médicas de Pedro Hispano, Coïmbra, Universidade de Coimbra (Acta universitatis Coninbrigensis).

Petrus Hispanus, URL: http://ifilosofia.up.pt/meirinhos/petrushispanus/ph [consulta: 18/01/2017].

Riera i Sans, Jaume (1989), Catàleg d'obres en català traduïdes en castellà durant els segles XIV i XV, en Ferrando, Antoni (ed.), Segon Congrés Internacional de la Llengua Catalana (1986), Àrea 7. Història de la llengua, València, Institut de Filologia Valenciana, vol. VIII, pp. 699-709.

Santanach i Suñol, Joan (2003), Introducció, en Grewe, Rudolf; Soberanas i Lleó, Amadeu Jesús; Santanach, Joan (eds.), Llibre de totes maneres de confits, Barcelona, Barcino, pp. 237-296 (Els Nostres Clàssics; B 22).

Santanach i Suñol, Joan (2006), Introducció, en Santanach, Joan (ed.), Llibre de Sent Soví, prefaci de Carme Ruscalleda, Barcelona, Barcino, pp. 11-38 (Biblioteca Barcino; 4).

Santanach i Suñol, Joan (2010), El Llibre de Sent Soví, les seves "versions" i la circulació de textos culinaris medievals, "Medioevo Romanzo" 34/2, pp. 352-395.

Santanach i Suñol, Joan (2015), De la cuina al taller de còpia (Sobre l'elaboració $i$ el consum de llibres de cuina a la tardor medieval catalana), "Estudis Romànics" 37, pp. 271-299. 
Santanach i Suñol, Joan (2015), Textos mèdics, morals i culinaris en un còdex valencià excepcional. Anàlisi del ms. 216 de la Biblioteca Històrica de la Universitat de València, "Caplletra. Revista internacional de filologia" 59, pp. 11-34.

Santanach i Suñol, Joan (en premsa), La Recepta de bona composta copiada a continuació del Pal-ladi de la Biblioteca Serrano Morales. Estudi i edició.

Tresor de pobres compilat per Petrus Hispanus. Versiò catalana del segle XIV (1892), [a cura de Josep Balari i Jovany?], Barcelona, Impremta Fidel Giró (Biblioteca de la Revista Catalana).

Vilanova, Arnau de (1947), Obres catalanes, II, Escrits mèdics, a cura de Miquel Batllori, pròleg de Joaquim Carreras i Artau, Barcelona, Barcino (Els Nostres Clàssics A; 55-56).

Fecha de recepción del artículo: abril 2014

Fecha de aceptación y versión final: febrero 2015 